\title{
Produção Sustentável do Óleo Essencial de Priprioca (Cyperus articulatus var. nodosus L.) na Amazônia
}

\author{
Michelly Rios Arévalo ${ }^{1}$, Inês Ribeiro Machado ${ }^{1}$, Amanda Sousa ${ }^{1}$, Kelly Cristina Ferreira ${ }^{1}$, Adilson Sartoratto ${ }^{2}$, \\ Marcos Ximenes Ponte ${ }^{3} \&$ Lauro Euclides Soares Barata ${ }^{1}$
}

Recebido em 26/10/2020 - Aceito em 09/03/2021

1 Universidade Federal do Oeste do Pará/UFOPA, Santarém/PA, Brasil.<michelly.arevalo@ufopa.edu.br, inesuenf@yahoo.com.br, amanda-
rodriguesxp@hotmail.com, kelly_quimica@yahoo.com.br, lauroesbarata@gmail.com>.
2 Universidade Estadual de Campinas/UNICAMP, Campinas/SP, Brasil. <adilson@cpqba.unicamp.br>.
3 Universidade Federal do Pará/UFPA, Belém/PA, Brasil. <ximenes@ufpa.br>.

RESUMO - Cyperus articulatus (Cyperaceae) é uma planta cujo tubérculo é utilizado na Amazônia para banhos de cheiro e perfumes caseiros. O óleo essencial (OE) da planta é empregado na perfumaria fina. A região do oeste do estado do Pará tem clima, terra e meios apropriados para o cultivo. Assim, o objetivo do trabalho foi a produção sustentável de C. articulatus em Comunidades locais, estabelecendo as bases de experimentos agronômicos para obtenção de parâmetros mínimos de um cultivo comercial. Foram instalados os experimentos Tabocal I e II (área de produtores) e Belterra (área da EMBRAPA). Optou-se por utilizar áreas agrícolas degradadas e analisar os fatores edafoclimáticos da região, obtendo-se coeficientes técnicos de produção aos 9 e 12 meses de cultivo. Aos 12 meses de cultivo, as melhores produções de tubérculos frescos de priprioca foram obtidas em Belterra 7,66t ha-1, Tabocal I 11,20t ha-1 e Tabocal II 22,09t ha-1. Os custos de produção por hectare foram estabelecidos para Belterra em $\mathrm{R} \$ 12.410,00$, Tabocal I em $\mathrm{R} \$ 15.740,00$ e Tabocal II em $\mathrm{R} \$ 12.460,00$. O lucro da produção de tubérculos para Belterra foi de $\mathrm{R} \$ 1.910,00$, Tabocal I com $\mathrm{R} \$ 6.660,00$ e Tabocal II com $\mathrm{R} \$ 31.734,00$. Foram estabelecidos parâmetros da extração e análise cromatográfica do óleo essencial dos tubérculosde priprioca em escala laboratorial, piloto e industrial. O rendimento médio no extrator piloto foi de $0,35 \%$, Clevenger igual a $0,56 \%$, e o industrial em $0,45 \%$. A análise do OE por Cromatografia de Gás acoplada à espectrometria de Massas (GC-MS) é discutida com base nas características dos experimentos. O perfil químico mostra terpenos característicos da espécie, como a mustacona, com variações de concentrações sujeitas aos fatores edafoclimáticos. A comercialização do $\mathrm{OE}$ praticada a US $\$ 500 / \mathrm{kg}$ mostra-se como uma nova alternativa econômica para a região.

Palavras-chave: Cultivo; custos de produção; óleo essencial; análise cromatográfica.

\section{Sustainable Production of the Priprioca Essential Oil (Cyperus articulatus var. nodosus L.) in Amazonia}

ABSTRACT - The Cyperus articulatus (Cyperaceae) is a plant used in the Amazon for bath scents. The essential oil (EO) from the plant is used by cosmetic industries to make fine fragrances. The region of West Pará State has climate, land and means suitable for cultivation. The objective of the work is the sustainable production of $C$. articulatus establishing the basis for agronomic experiments in degraded areas to obtain the minimal parameters for commercial cultivation. They were installed experiments Tabocal I and II (area producers) and Belterra (area of EMBRAPA). The availability of agricultural areas and the edafoclimatic factors in the region were considered, obtaining technical coefficients of production after 09 and 12 months of planting. The best production of fresh priprioca bulbs was after 12 months of planting, in Belterra, with 7.66t ha- ${ }^{-1}$, in Tabocal I 11.20t ha ${ }^{-1}$ and in Tabocal II 22.09t ha-1. The cost of production per hectare varied. In Belterra it was $R \$ 12,410.00$, in Tabocal II $R \$ 15,740.00$ and in Tabocal II $\mathrm{R} \$ 12,460.00$. The profits, or the net gain of the production of bulbs for Belterra was $\mathrm{R} \$ 1,910.00$, for Tabocal I $R \$ 6,660.00$ and for Tabocal II $R \$ 31,734.00$. They were established extraction and chromatographic analysis of the essential oil of priprioca tubers in laboratory scale, pilot and industrial. The yield on the pilot extractor was $0.35 \%$, Clevenger of $0.56 \%$ and $0.45 \%$ in the industry. A complementary chromatographic analysis of the $\mathrm{EO}$ of the priprioca is discussed based 
on the characteristics of the experiments. The chemical profile shows sesquiterpenes characteristic for this species, such as mustacone with variations of concentrates subject to edafoclimatic factors. The commercialization of the EO at US\$500/kg shows that the cultivation of priprioca presents itself as a new economic alternative in the region.

Keywords: Cultivation; production costs; essential oil; chromatographic analysis.

\section{Producción Sostenible de Aceite Esencial de Priprioca (Cyperus articulatus var. nodosus L.) en la Amazonía}

RESUMEN - Cyperus articulatus (Cyperaceae) es una planta cuyo tubérculo se utiliza en la Amazonía para baños olorosos y perfumes caseros. El aceite esencial (OE) de la planta también es utilizado en la perfumería fina. La región occidental del Estado de Pará cuenta con clima, tierra y medios apropiados para el cultivo. Así, el objetivo del trabajo fue la producción sostenible de C. articulatus en comunidades locales, mediante experimentos agronómicos para obtener parámetros mínimos de un cultivo comercial. Se instalaron los experimentos Tabocal I y II (área de agricultores) y Belterra (área EMBRAPA). Se optó por utilizar áreas agrícolas degradadas y analizar los factores edafoclimáticos de la región, obteniendo coeficientes técnicos de producción a los 09 y 12 meses de cultivo. A los 12 meses de cultivo, los mejores rendimientos de tubérculos frescos de priprioca se obtuvieron en Belterra 7,66t ha-1, Tabocal I 11,20t ha-1 y Tabocal II 22,09t ha-1 . Los costos de producción por hectárea para Belterra fue de $\mathrm{R} \$ 12.410,00$, Tabocal I en $\mathrm{R} \$ 15.740,00$ y Tabocal II en $\mathrm{R} \$ 12.460,00$. El gaño de la producción de tubérculos para Belterra fue de $\mathrm{R} \$ 1.910,00$, Tabocal I con $\mathrm{R} \$ 6.660,00$ y Tabocal II con $\mathrm{R} \$ 31.734,00$. Los parámetros cromatográficos de extracción y análisis de aceite esencial de tubérculos de priprioca se estableció en escala de laboratorio, piloto e industrial. El rendimiento promedio en el extractor piloto fue de $0.35 \%$, Clevenger igual a $0.56 \%$ y el industrial en $0.45 \%$. El análisis de OE por cromatografía de gases acoplada a espectrometría de masas (GC-MS) es discutida con base a las características de los experimentos. El perfil químico muestra terpenos característicos de la especie, como la mustacona, con variaciones en concentraciones sujetas a factores edafoclimáticos. La comercialización de OE practicada a US\$ 500/kg es una nueva alternativa económica para la región.

Palabras clave: Cultivo; costos de producción; aceite esencial; análisis cromatográfico.

\section{Introdução}

Da família Cyperaceae, o gênero Cyperus tem distribuição cosmopolita (Adams, 1994) e importância biológica, medicinal e química (Potiguara \& Zoghbi, 2008). O recente uso na indústria de cosméticos e perfumaria no Brasil estimulou estudos dirigidos à obtenção do óleo essencial (OE) de diferentes espécies de Cyperus (Nicoli et al., 2006; Potiguara \& Zoghbi, 2008; Barata, 2012).

Na Amazônia brasileira, algumas espécies da família Cyperaceae são conhecidas pela denominação popular de priprioca (Potiguara \& Zoghbi, 2008). No estado do Pará, empresas locais de perfumaria utilizam o extrato da priprioca em seus produtos há décadas. O tubérculo da planta é explorado por artesãos, por micro e por pequenas empresas da região, como a Juruá e a Chamma da Amazônia. No entanto, o OE é explorado em escala comercial apenas pela empresa Beraca, com produção eventualmente exclusiva para a empresa de cosméticos e perfumes Natura.
Nos últimos anos, a priprioca tem sido cultivada de forma intensiva, gerando fonte de renda para comunidades de agricultores paraenses (Potiguara \& Zoghbi, 2008), onde a produção anual é determinada pela indústria. Não existe registro de produção comercial de $\mathrm{OE}$ de $C$. articulatus em outras regióes do mundo, embora o $\mathrm{OE}$ de C. scariosus conhecido como "Nagarmotha" ou "Cyprol" seja comercializado a US\$ 266,67/L (Lala's Group). A produção de priprioca não tem registros específicos de comercialização no Pará e nem registros de exportação internacional do óleo essencial de priprioca no MDIC (Ministério do Desenvolvimento Indústria e Comércio).

A indústria de cosméticos e perfumaria mundial demanda frequentemente matérias primas para a formulação de novos aromas e fragrâncias. $\mathrm{Na}$ Amazônia, apesar de haver registros de 1.250 plantas aromáticas (Maia et al., 2001), são poucas as plantas aproveitadas de modo comercial. Originadas majoritariamente por extrativismo florestal, são commodities, como o óleo resina de copaíba (Copaifera spp.), sementes de cumarú 
(Dipteryx odorata) e óleo essencial do pau-rosa (Aniba rosaeodora) que estão entre as principais para exportação e comércio (Ferraz et al., 2009). Atualmente, inclui-se a priprioca também usada na perfumaria fina pela sua qualidade olfativa do seu $\mathrm{OE}$, vantagem dada pela sua complexa composição química rico em sesquiterpenos e diterpenos, o que eleva sua importância comercial, tornando difícil a recomposição sintética da fragrância. Potiguara \& Zoghbi (2008) analisando quimicamente algumas espécies de priprioca por cromatografia gasosa encontraram que a $C$. articulatus var. nodosus apresentou entre seus principais componentes os monoterpenosalfa-pineno, beta-pineno, trans-pinocarveol, mirtenal+mirtenol, e os sesquiterpenos alfa-copaeno, cipereno, betaselineno, ledol, óxido de cariofileno, epóxido de humuleno II, eudesma-3,11-dien-5-ol, 14-hidróxi9-epi-beta-cariofileno, isociperol, mustacona, ciperol, ciperotundona e alfa-ciperona.

Estudos agronômicos da priprioca ressaltam que o tratamento de $20 \mathrm{t} \mathrm{ha}{ }^{-1}$ de cama de aviário com distanciamento de plantas de 0,20 x 0,20m resultou com 32 tha $^{-1}$ de tubérculos e um rendimento de $\mathrm{OE}$ de $0,63 \%$ extraído em Clevengerpor três horas (Potiguara \& Zoghbi, 2008). Foram também satisfatórios os tratamentos com NPK $\left(18,62 \mathrm{t} \mathrm{ha}^{-1}\right)$ e cinza $\left(17,96 \mathrm{t} \mathrm{ha}^{-1}\right)$. Na região, adubos de esterco de bovino e a cama de frango de corte são os mais utilizados na produção de hortaliças e mudas de frutíferas (Teixeira et al., 2006).

Em visita exploratória à região Metropolitana de Belém em 2011, foram registrados casos $\mathrm{de}$ agricultores que não realizaram a capina de priprioca após as primeiras fases de crescimento do cultivo, mas possibilita uma colheita dos tubérculos para ser comercializado a $\mathrm{R} \$ 4,00 \mathrm{~kg}$. O preparo do solo, o plantio e o manejo cultural (capina) da priprioca é manual, demandando um grande esforço físico no campo. Alternativas mecanizadas deste cultivo podem reduzir o esforço do homem no campo como a possibilidade de aumentar asáreas de produção.

O cultivo de plantas nativas na região amplia as chances de mercado para comunidades e empresas locais. O cultivo da priprioca no oeste do Pará busca novas alternativas produtivas sustentáveis na Amazônia, e visa à preservação do ambiente e a elevação da qualidade de vida (Fontanétti et al., 2006). Por isso, o objetivo deste trabalho foi implantar três módulos experimentais de plantio de priprioca em áreas degradadas com a finalidade de ampliar áreas produtivas de priprioca e gerar novas alternativas econômicas no campo agrícola. Foram analisados os fatores edafoclimáticos da região, comparando-se os parâmetros físico-químicos do solo e de nutrientes versus rendimento e concentrações de substâncias químicas do óleo essencial em cada experimento. Compararam-se os custos de produção dos tubérculos dos campos experimentais frente à disponibilidade de insumos, mão de obra local, equipamentos agrícolas, transporte e extração do $\mathrm{OE}$, estabelecendo um preço mínimo do produto condizente com a realidade da região.

\section{Material e Métodos}

Os experimentos do cultivo de priprioca (C. articulatus var. nodosus) no oeste do Pará localizaram-se no município de Santarém, Comunidade de Tabocal I (-54'71'71,02"W e $\left.-02^{\circ} 62^{\prime} 85,33^{\prime \prime} \mathrm{S}\right)$ e Tabocal II $\left(-54^{\circ} 74^{\prime} 04,59^{\prime \prime} \mathrm{W}\right.$ e -0262'38,48'S) e município de Belterra

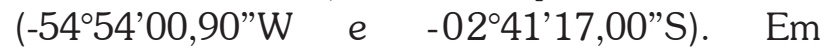
2012 foi montado o experimento "Tabocal I" propriedade do senhor Moreira, e "Belterra" na área experimental da EMBRAPA. Em 2013 foi montado o experimento "Tabocal II" propriedade da família Galo.

Foram consideradosos parâmetros ambientais como temperatura, precipitação $e$ umidade relativa da região obtidos da estação Meteorológica OMM: 82246 (BDMEP-INMET/ Belterra/PA). A análise do solo foi analisada em laboratório da Embrapa Amazônia Oriental (Belém/PA) e no laboratório agropecuário Plante Certo Ltda. (Mato Grosso/MT).

Para o primeiro plantio, em 2012, foram adquiridos rizomas do município Santo Antônio de Tauá, região Metropolitana de Belém. O plantio de 2013 foi estabelecido com rizomas do experimento 2012. Uma amostra do cultivo 2012 foi depositada no Herbário Museu Paraense Emílio Goeldi com registro n ${ }^{\circ} 207174$. O tamanho dos experimentos foi de 0,12ha, em Tabocal I; 0,25ha, em Tabocal II; e 1,0ha, em Belterra. Foram construídos canteiros nas dimensões de $48 \mathrm{~m}^{2}(1,20 \mathrm{x} 40,0 \mathrm{~m})$ em Tabocal I e $60 \mathrm{~m}^{2}(1,20 \mathrm{x}$ $50,0 \mathrm{~m})$ em Belterra e Tabocal II, com espaçamento entre canteiros de $0,50 \mathrm{~m}$. Incorporou-se $15 \mathrm{tha}^{-1}$ de adubo orgânico de cama de frango curtido. A análise de disponibilidade de nutrientes do adubo foi realizada pela empresa Plante Certo Ltda. 
Nos canteiros, o espaçamento dos rizomas foi de $0,40 \times 0,40 \mathrm{~m}$ ou 375 rizomas/canteiro de $60 \mathrm{~m}^{2}$, enterrados em covas de $5 \mathrm{~cm}$ de profundidade. $\mathrm{O}$ combate ao mato foi realizado por capina manual segundo o grau de infestação, sendo necessárias 3 a 5 incursões durante o experimento. Em Tabocal I e Belterra, comparou-se: a) o rendimento de canteiros limpos; e b) canteiros em competição direta com ervas daninhas. Em Tabocal II, comparou-se: a) canteiros com incorporação de cama de frango com enxada rotativa; e b) canteiros com incorporação manual do adubo, estas duas últimas mantidas capinadas durante todo o experimento.

$\mathrm{O}$ custo de produção foi contabilizado após nove e doze meses de cultivo, considerando a mão de obra para implantação, capina $e$ limpeza dos tubérculos, como também insumos e transporte. O rendimento do óleo essencial do tubérculo da priprioca (\%) foi realizado em laboratório P\&DBIO - Laboratório de Pesquisa \& Desenvolvimento de Produtos Naturais Bioativos, UFOPA (hidrodestilação em Clevenger e extrator piloto em aço inox de 150L) e em equipamento industrial (dorna de aço inox de 2.000L). No estudo laboratorial, optou-se por tubérculos com um ano de cultivo oriundos dos três experimentos e, para a análise industrial, optou-se por tubérculos do experimento Tabocal I em 2014, especificamente com tubérculos de dois anos de cultivo. As amostras frescas retiradas do campo variaram de $5-15 \mathrm{~kg}$, para laboratório, e de 1 tonelada na indústria. $\mathrm{Na}$ secagem dos tubérculos as estufas foram reguladas a $60^{\circ} \mathrm{C}$ por 3 dias consecutivos, para secagem industrial, se contou com a colaboração da Empresa Algine, em Santarém, no Pará. Depois de secos, os tubérculos foram triturados. O tempo de extração do óleo foi de 3 horas em laboratório e 6 horas na indústria (padrão industrial).

Em novembro de 2014 (verão amazônico), um novo lote de tubérculos foi coletado dos três experimentos para o estudo do perfil químico do óleo essencial da priprioca. O estudo cromatográfico (GC-MS) foi realizado no CPQBA-UNICAMP utilizando um cromatógrafo a gás Agilent, modelo HP-6890 equipado com detetor seletivo de massas Agilent, modelo HP-5975, coluna capilar HP-5MS ( $30 \mathrm{~m} \times 0,25 \mathrm{~mm} \times 0,25 \mu \mathrm{m}$ ) nas seguintes condições: temperatura do injetor $=220^{\circ} \mathrm{C}$, coluna $=60^{\circ} \mathrm{C}$, taxa de aquecimento de $3^{\circ} \mathrm{C} \cdot \mathrm{min}^{-1}$ até $240^{\circ} \mathrm{C}$ e detetor $=250^{\circ} \mathrm{C}$. Hélio foi utilizado como gás de arraste numa vazão de $1 \mathrm{~mL} \cdot \mathrm{min}^{-1}$. Detetor seletivo de massas operando a $70 \mathrm{eV}, \mathrm{m} / \mathrm{z}=30 \mathrm{a}$ 500u.m.a. Para a injeção, o óleo foi solubilizado em acetato de etila na concentração de $20 \mathrm{mg} \cdot \mathrm{ml}^{-1}$, e a identificação foi realizada através do cálculo dos índices de retenção dos analitos, utilizandose a co-injeção de uma mistura de padrões de hidrocarbonetos (C8 a C22), comparação com a biblioteca eletrônica do equipamento (NIST-11) e com dados da literatura (Adams, 2007).

\section{Resultados e Discussão}

\section{Condições do clima no oeste do Pará}

Cultivos de priprioca na Amazônia só são registrados na região de Belém (Potiguara \& Zoghbi, 2008; Castellani et al., 2011). Introduzir a priprioca no oeste do Pará implicou conhecer o clima da região, principalmente a distribuição das chuvas que é menor que em Belém. Moraes et al. (2005) mostram que a precipitação média anual em várias localidades do estado do Pará tem ampla variação, com uma precipitação de $1678 \mathrm{~mm}$, em Monte Alegre (próximo a Santarém), região central do estado, e $3216 \mathrm{~mm}$ em Soure, na Ilha do Marajó (próxima a Belém).

Já os dados coletados do BDMEP-INMET/ Belterra/PA, durante o experimento, reafirmam a publicação de Silva et al. (2013), onde a região oeste do Pará tem um regime pluviométrico dividido em dois períodos: chuvoso (janeiro a junho) e menos chuvoso (agosto a novembro). A diminuição das médias mensais de umidade relativa e o aumento da temperatura máxima estão em estreita relação com a temporada da seca na região, e inversamente com a época das chuvas. É recomendável implantar o cultivo da priprioca assim que iniciar a época das chuvas na região.

\section{A condição do solo no oeste do Pará}

O solo predominante da região é classificado como latossolo amarelo (Cravo et al., 2010). Nos experimentos foi priorizada a utilização de solos sem uso agrícola há, pelo menos, dois anos. A granulometria do solo mostrou que Tabocal I é bastante arenoso; já Tabocal II e Belterra, argilosos. O pH dos solos variou em 5,0; 5,5 e 4,6, respectivamente. A disponibilidade de Nitrogênio $(\mathrm{N})$ em Tabocal I foi de 0,19\% e Belterra com 0,41\%. Os teores de matéria orgânica corresponderam com 5,10; 34,0 e 6,39 g/kg respectivamente. O fósforo (P) disponível em 2,0; 7,0 e 14,0mg/dm ${ }^{3}$ e 
o Potássio (K) com 25,0; 67,0 e 60,0mg/dm³. Sódio (Na) em Tabocal I com $17,0 \mathrm{mg} / \mathrm{dm}^{3}$ e em Belterra $34,0 \mathrm{mg} / \mathrm{dm}^{3}$. Cálcio (Ca) com 2,3; 2,0 e 4,6 $\mathrm{cmol}_{\mathrm{d}}$ $\mathrm{dm}^{3}$. A relação $\mathrm{Ca}+\mathrm{Mg}$ com 3,0; 2,6 e 5,8 $\mathrm{cmol}_{d}$ $\mathrm{dm}^{3}$. Alumínio (Al) com 0,$3 ; 0,8$ e $0,0 \mathrm{cmol}_{d} / \mathrm{dm}^{3}$. A relação $\mathrm{H}+\mathrm{Al}$ com 3,$8 ; 6,7$ e $5,2 \mathrm{cmol}_{d} / \mathrm{dm}^{3}$. Cobre $(\mathrm{Cu}) \operatorname{com} 1,3 ; 2,5$ e 0,6 $\mathrm{cmol}_{\mathrm{c}} / \mathrm{dm}^{3}$. Manganês (Mn) com 11,6 e $15,8 \mathrm{cmol}_{d} / \mathrm{dm}^{3}$ e $31,20 \mathrm{mg} / \mathrm{dm}^{3}$. Ferro (Fe) com 99,6 e 63,4 $\mathrm{cmol}_{/} / \mathrm{dm}^{3}$ e $77,0 \mathrm{mg} / \mathrm{dm}^{3}$. Zinco (Zn) com 1,0 e $0,3 \mathrm{cmol} / \mathrm{dm}^{3}$ e $2,5 \mathrm{mg} / \mathrm{dm}^{3}$. A Capacidade de Troca de cátions (CTC) com 3,54 e $3,32 \mathrm{cmol}_{c} / \mathrm{dm}^{3}$ e $11,3 \mathrm{mg} / \mathrm{dm}^{3}$. Por último, a Saturação de Bases (V\%) foi igual a 45,23 e $30,13 \mathrm{cmol}_{c} / \mathrm{dm}^{3}$ e $53,30 \mathrm{mg} / \mathrm{dm}^{3}$.

A literatura científica não indica a disponibilidade suficiente de nutrientes para o melhor desenvolvimento da priprioca, por outro lado, estudos mostram que a demanda por adubo orgânico no cultivo da priprioca é alta, 18t ha-1 aproximadamente (Potiguara \& Zoghbi, 2008). No experimento foi incorporada a proporção de $15 \mathrm{t} \mathrm{ha}^{-1}$ de adubo orgânico (cama de frango decomposta). A proporcionalidade de nutrientes a ser disponibilizadas pelo adubo de frango na área experimental (15t ha $\left.{ }^{-1}\right)$ foi de $273,00 \mathrm{~kg} \mathrm{~N} / \mathrm{ha}$, $828,00 \mathrm{~kg} \mathrm{P}_{2} \mathrm{O}_{5} / \mathrm{ha}, 451,50 \mathrm{~kg} \mathrm{~K} 2 \mathrm{O} / \mathrm{ha}, 1120,50 \mathrm{~kg}$ $\mathrm{Ca} / \mathrm{ha}, 114,00 \mathrm{~kg} \mathrm{Mg} / \mathrm{ha}, 57 \mathrm{~kg} \mathrm{~S} / \mathrm{ha}, 9,96 \mathrm{~kg} \mathrm{Zn} /$ ha, $2,55 \mathrm{~kg} \mathrm{Cu} / \mathrm{ha}, 42,15 \mathrm{~kg} \mathrm{Fe} / \mathrm{ha}, 7,14 \mathrm{~kg} \mathrm{Mn} / \mathrm{ha}$ e $0,85 \mathrm{~kg} \mathrm{~B} / \mathrm{ha}$. Já a disponibilidade de matéria orgânica do adubo foi igual $673,9 \mathrm{~kg} / \mathrm{t}$.

\section{A produção agrícola de priprioca no oeste do Pará}

Na campanha agrícola de 2012, rizomas de priprioca foram obtidos na região de Belém e levados à Santarém para início dos trabalhos. O rizoma quando coletado tem uma brotação acelerada devido à umidade recebida na limpeza. Foram utilizados sacos de polietileno com tramas para perda da umidade durante o transporte, evitando também a proliferação de microorganismos. Em 2013, na segunda campanha agrícola da priprioca, contou-se com rizomas reproduzidos na campanha 2012 em Santarém.

A priprioca é um cultivo produzido só com adubo orgânico no Pará. O trabalho no campo agrícola é manual, o que exige elevado número de mão de obra, reduz a capacidade de aumento de produção e produtividade e deixa-se de obter maiores rendimentos (Potiguara \& Zoghbi, 2008). Durante os experimentos, foi constatado que a região de Santarém possui limitações de mão de obra no campo agrícola. A estratégia para o deslocamento de mão de obra aumentou os custos de remuneração pelo serviço prestado (diárias).

A campanha agrícola de 2012 em Santarém caracterizou-se amplamente pelo trabalho manual, iniciada com limpeza da área experimental $e$ a construção dos canteiros, prosseguindo pela incorporação de adubo orgânico (cama de frango). Na campanha 2013, com a participação de uma família produtora de grãos, foram usados equipamentos agrícolas como grade e enxada rotativa. Não foram observados efeitos de pragas e doenças no cultivo.

\section{Análise de custos de produção no oeste do Pará}

O cultivo da priprioca demanda atividades simples e principalmente uma alta dependência de mão de obra (Silva, 2005; Castellani et al., 2011), o que pode ser um dado positivo para gerar novas oportunidades de emprego e renda no campo. Os custos de produção local do cultivo priprioca foram estabelecidos para Belterra (Tabela 1), Tabocal I (Tabela 2) e Tabocal II (Tabela 3). A rentabilidade bruta e líquida da produção local da priprioca foi calculada a partir do preço de $\mathrm{R} \$ 2,00 \mathrm{~kg} /$ tubérculo fresco, valor aceitável para diversificar e criar novas alternativas econômicas no campo.

\section{Experimento Belterra}

A Tabela 1 mostra que a produção de tubérculos aos nove meses de cultivo atingiu 4,00t ha-1 em áreas capinadas e 2,25t ha ${ }^{-1}$ em áreas não capinadas. Aos 12 meses de cultivo, coincidindo com as novas chuvas da região a produção subiu para 7,66t ha-1 em áreas capinadas e 3,88t ha-1 em áreas não capinadas, um aumento de $91,5 \%$ e $72,44 \%$ respectivamente.

O custo de produção total em Belterra quando projetados em hectare foi de $\mathrm{R} \$ 12.410,00$ um custo elevado pela dependência de mão de obra. No entanto, considerando a área que não recebeu a labor de capina, o custo para um hectare foi de $R \$ 10.010,00$.

Quanto ao rendimento econômico bruto e líquido de produção de tubérculos frescos de priprioca quando comercializados ao preço de $\mathrm{R} \$ 2,00 \mathrm{~kg}$ em Santarém, o experimento em 
nove meses de produção em Belterra tem saldos negativos assim que descontado os custos de produção. Somente aos 12 meses de cultivo a produção tem um retorno lucrativo com $\mathrm{R} \$$ $2.910,00$.

Tabela 1 - Experimento Belterra 2012, coeficientes técnicos, custos de produção e rendimento de implantação de cultivo de priprioca (Cyperus articulatus var. nodosus) projetada em hectare aos 09 e 12 meses de cultivo.

\begin{tabular}{|c|c|c|c|c|c|c|c|c|}
\hline Atividades & Unidade & Quantidade & $\begin{array}{c}\text { Valor } \\
\text { unitário } \\
(\mathbf{R} \$)\end{array}$ & $\begin{array}{c}\text { Mão de } \\
\text { obra } \\
\text { (área I) }\end{array}$ & $\begin{array}{c}\text { Mão de } \\
\text { obra } \\
\text { (área } \\
\text { II) }\end{array}$ & $\begin{array}{l}\text { RB valor } \\
\text { total (R\$) }\end{array}$ & $\begin{array}{c}\text { Área I } \\
\text { custo } \\
\text { total }(\mathrm{R} \$)\end{array}$ & $\begin{array}{c}\text { Área II } \\
\text { custo } \\
\text { total } \\
(\mathbf{R} \$)\end{array}$ \\
\hline \multicolumn{9}{|l|}{ Preparo e implantação da área } \\
\hline - Limpeza da área & mão de obra & 13,00 & 30,00 & 13,00 & 13,00 & 390,00 & 390,00 & 390,00 \\
\hline $\begin{array}{l}\text { - Preparo de canteiros e } \\
\text { instalação de cultivo }\end{array}$ & mão de obra & 94,00 & 30,00 & 94,00 & 94,00 & $2.820,00$ & $2.820,00$ & $2.820,00$ \\
\hline \multicolumn{9}{|l|}{ Tratos culturais } \\
\hline - Capina $2^{\circ}$ mês & mão de obra & 47,00 & 30,00 & 47,00 & - & $1.410,00$ & $1.410,00$ & \\
\hline - Capina $4^{\circ}$ mês & mão de obra & 23,00 & 30,00 & 23,00 & - & 690,00 & 690,00 & \\
\hline - Capina $7^{\circ}$ mês & mão de obra & 10,00 & 30,00 & 10,00 & - & 300,00 & 300,00 & \\
\hline \multicolumn{9}{|l|}{ Insumos } \\
\hline - Sementes ou rizomas & $\mathrm{kg}$ & 300,00 & 4,00 & & & $1.200,00$ & $1.200,00$ & $1.200,00$ \\
\hline - Adubo orgânico & t ha- ${ }^{1}$ & 15,00 & 120,00 & & & $1.800,00$ & $1.800,00$ & $1.800,00$ \\
\hline - Transporte adubo & t ha- ${ }^{1}$ & 2,00 & 350,00 & & & 700,00 & 700,00 & 700,00 \\
\hline \multicolumn{9}{|l|}{ Colheita e beneficiamento } \\
\hline - Colheita & mão de obra & 40,00 & 30,00 & 40,00 & 40,00 & $1.200,00$ & $1.200,00$ & $1.200,00$ \\
\hline - Lavagem & mão de obra & 40,00 & 30,00 & 40,00 & 40,00 & $1.200,00$ & $1.200,00$ & $1.200,00$ \\
\hline - Transporte $\mathrm{p} /$ beneficiamento & frete & 2,00 & 350,00 & & & 700,00 & 700,00 & 700,00 \\
\hline Custo total de produção & & & & 267,00 & 187,00 & $12.410,00$ & $12.410,00$ & $10.010,00$ \\
\hline Preço de priprioca em Santarém & $\mathrm{Kg}$ & 1,00 & 2,00 & & & & & \\
\hline RL área I (9 meses) & Kg ha- ${ }^{1}$ & $4.000,00$ & 2,00 & & & $8.000,00$ & $-4.410,00$ & \\
\hline RL área I (12 meses) & Kg ha- ${ }^{1}$ & $7.660,00$ & 2,00 & & & $15.320,00$ & $2.910,00$ & \\
\hline RL área II (9 meses) & $\mathrm{Kg} \mathrm{ha}^{-1}$ & $2.250,00$ & 2,00 & & & $4.500,00$ & & $-5.510,00$ \\
\hline RL área II (12 meses) & Kg ha- ${ }^{1}$ & $3.883,00$ & 2,00 & & & $7.766,00$ & & $-2.244,00$ \\
\hline
\end{tabular}

$\mathrm{RB}=$ Rendimento Bruto

Área I = com capina

$\mathrm{RL}=$ Rendimento Líquido

Área II = sem capina

\section{Experimento Tabocal I}

A Tabela 2, aos nove meses da produção, mostra um rendimento de tubérculos de $5,84 \mathrm{t} \mathrm{ha}^{-1}$ em áreas capinadas e $1,25 \mathrm{t} \mathrm{ha}^{-1}$ em áreas não capinadas. Aos doze meses, houve um incremento para 11,20t ha-1 em áreas limpas e 2,39t ha-1 em áreas não limpas, um aumento de $91,78 \%$ e $91,20 \%$ respectivamente.
O custo de produção total na área experimental em Tabocal I foi de $\mathrm{R} \$ 15.740,00$. Custo considerado elevado pela dependência de mão de obra. Assim, mesmo a área que não recebeu trato cultural, o custo de um hectare ficou em $\mathrm{R} \$$ 8.870,00. 
Tabela 2 - Experimento Tabocal I, coeficientes técnicos, custos de produção e rendimento de implantação de cultivo de priprioca (Cyperus articulatus var. nodosus) projetada em hectare aos 09 e 12 meses de cultivo.

\begin{tabular}{|c|c|c|c|c|c|c|c|c|}
\hline Atividades & Unidade & Quantidade & $\begin{array}{c}\text { Valor } \\
\text { unitário } \\
(\mathbf{R} \$)\end{array}$ & $\begin{array}{c}\text { Mão de } \\
\text { obra } \\
\text { (área I) }\end{array}$ & $\begin{array}{c}\text { Mão de } \\
\text { obra } \\
\text { (área II) }\end{array}$ & $\begin{array}{c}\text { RB valor } \\
\text { total }(\mathbf{R} \$)\end{array}$ & $\begin{array}{c}\text { Área I } \\
\text { custo } \\
\text { total }(\mathbf{R} \$)\end{array}$ & $\begin{array}{c}\text { Área II } \\
\text { custo } \\
\text { total } \\
(\mathrm{R} \$)\end{array}$ \\
\hline \multicolumn{9}{|l|}{ Preparo e implantação da área } \\
\hline - Limpeza da área & mão de obra & 19,00 & 30,00 & 19,00 & 19,00 & 570,00 & 570,00 & 570,00 \\
\hline $\begin{array}{l}\text { - Preparo de canteiros e } \\
\text { instalação de cultivo }\end{array}$ & mão de obra & 36,00 & 30,00 & 36,00 & 36,00 & $1.080,00$ & $1.080,00$ & $1.080,00$ \\
\hline \multicolumn{9}{|l|}{ Tratos culturais } \\
\hline - Capina $2^{\circ}$ mês & mão de obra & 132,00 & 30,00 & 132,00 & - & $3.960,00$ & $3.960,00$ & - \\
\hline - Capina $4^{\circ}$ mês & mão de obra & 97,00 & 30,00 & 97,00 & - & $2.910,00$ & $2.910,00$ & - \\
\hline \multicolumn{9}{|l|}{ Insumos } \\
\hline - Sementes ou rizomas & $\mathrm{kg}$ & 300,00 & 4,00 & & & $1.200,00$ & $1.200,00$ & $1.200,00$ \\
\hline - Adubo orgânico & tha-1 & 15,00 & 120,00 & & & $1.800,00$ & $1.800,00$ & $1.800,00$ \\
\hline - Transporte adubo & tha- ${ }^{1}$ & 2,00 & 350,00 & & & 700,00 & 700,00 & 700,00 \\
\hline \multicolumn{9}{|l|}{ Colheita e beneficiamento } \\
\hline - Colheita & mão de obra & 47,00 & 30,00 & 47,00 & 47,00 & $1.410,00$ & $1.410,00$ & $1.410,00$ \\
\hline - Lavagem & mão de obra & 47,00 & 30,00 & 47,00 & 47,00 & $1.410,00$ & $1.410,00$ & $1.410,00$ \\
\hline - Transporte $\mathrm{p} /$ beneficiamento & Frete & 2,00 & 350,00 & & & 700,00 & 700,00 & 700,00 \\
\hline Custo total de produção & & & & 378,00 & 149,00 & $15.740,00$ & $15.740,00$ & $8.870,00$ \\
\hline Preço de priprioca em Santarém & $\mathrm{Kg}$ & 1,00 & 2,00 & & & & & \\
\hline RL área I (9 meses) & $\mathrm{Kg}_{\mathrm{ha}}{ }^{-1}$ & $5.844,08$ & 2,00 & & & $11.688,16$ & $-4.051,84$ & \\
\hline RL área I (12 meses) & $\mathrm{Kg}_{\mathrm{ha}-}{ }^{1}$ & $11.200,00$ & 2,00 & & & $22.400,00$ & $6.660,00$ & \\
\hline RL área II (9 meses) & $\mathrm{Kg}_{\mathrm{ha}}{ }^{-1}$ & $1.250,00$ & 2,00 & & & $2.500,00$ & & $-6.370,00$ \\
\hline RL área II (12 meses) & $\mathrm{Kg} \mathrm{ha-}^{-1}$ & $2.393,00$ & 2,00 & & & $4.786,00$ & & $-4.084,00$ \\
\hline
\end{tabular}

$\mathrm{RB}=$ Rendimento Bruto

Área 1 = com capina

$\mathrm{RL}=$ Rendimento Líquido

Área 2 = sem capina

Quanto ao rendimento econômico bruto e líquido de produção de tubérculos frescos, a Tabela 2 mostra que o experimento aos nove meses de produção apresenta também saldo negativo na comercialização assim que descontado os custos de produção. Somente aos 12 meses de cultivo a produção tem um retorno lucrativo de $\mathrm{R} \$ 6.660,00$ por hectare produzido.

\section{Experimento Tabocal II}

A Tabela 3 mostra que aos nove meses de cultivo foram atingidos $18,41 \mathrm{t}$ ha ${ }^{-1}$ de tubérculos nas leiras onde foi incorporado adubo orgânico ao solo com ajuda da enxada rotativa, e 11,08t ha $^{-1}$ na área onde a aplicação do adubo foi de forma manual. Aos 12 meses de cultivo, houve um incremento para 22,09t ha-1 e 13,85t ha-1, resultando num aumento de 19,98\% e 25,00\% respectivamente. Este experimento mostra que em nove meses houve um melhor desenvolvimento do cultivo, já aos doze meses houve um incremento menor aos primeiros experimentos. 
Tabela 3 - Experimento Tabocal II, coeficientes técnicos, custos de produção e rendimento de implantação de cultivo de priprioca (Cyperus articulatus var. nodosus) projetada em hectare aos nove e doze meses de cultivo.

\begin{tabular}{|c|c|c|c|c|c|c|c|c|}
\hline Atividades & Unidade & Quantidade & $\begin{array}{c}\text { Valor } \\
\text { unitário } \\
(\mathbf{R} \$)\end{array}$ & $\begin{array}{c}\text { Mão de } \\
\text { obra } \\
\text { (área I) }\end{array}$ & $\begin{array}{c}\text { Mão de } \\
\text { obra } \\
\text { (área II) }\end{array}$ & $\begin{array}{c}\text { RB valor } \\
\text { total } \\
(\mathbf{R} \$)\end{array}$ & $\begin{array}{l}\text { Área I } \\
\text { custo } \\
\text { total } \\
(\mathbf{R} \$)\end{array}$ & $\begin{array}{c}\text { Área II } \\
\text { custo } \\
\text { total } \\
(\mathbf{R} \$)\end{array}$ \\
\hline \multicolumn{9}{|l|}{ Preparo e implantação da área } \\
\hline - I arado e limpeza da área & empreita & 1,00 & 120,00 & 1,00 & 1,00 & 120,00 & 120,00 & 120,00 \\
\hline - II arado & empreita & 1,00 & 120,00 & 1,00 & 1,00 & 120,00 & 120,00 & 120,00 \\
\hline - Arado enxada rotativa & empreita & 1,00 & 320,00 & 1,00 & - & 320,00 & 320,00 & \\
\hline - Delimitação de canteiros & mão de obra & 7,00 & 30,00 & 7,00 & 7,00 & 210,00 & 210,00 & 210,00 \\
\hline - Instalação do cultivo & mão de obra & 43,00 & 30,00 & 43,00 & 43,00 & $1.290,00$ & $1.290,00$ & $1.290,00$ \\
\hline \multicolumn{9}{|l|}{ Tratos culturais } \\
\hline - Capina $2^{\circ}$ mês & mão de obra & 40,00 & 30,00 & 40,00 & 40,00 & $1.200,00$ & $1.200,00$ & $1.200,00$ \\
\hline - Capina $3^{\circ}$ mês & mão de obra & 40,00 & 30,00 & 40,00 & 40,00 & $1.200,00$ & $1.200,00$ & $1.200,00$ \\
\hline - Capina $4^{\circ}$ mês & mão de obra & 40,00 & 30,00 & 40,00 & 40,00 & $1.200,00$ & $1.200,00$ & $1.200,00$ \\
\hline - Capina $5^{\circ}$ mês & mão de obra & 20,00 & 30,00 & 20,00 & 20,00 & 600,00 & 600,00 & 600,00 \\
\hline \multicolumn{9}{|l|}{ Insumos } \\
\hline - Sementes ou rizomas & $\mathrm{kg}$ & 300,00 & 4,00 & & & $1.200,00$ & $1.200,00$ & $1.200,00$ \\
\hline - Adubo orgânico & tha- ${ }^{1}$ & 15,00 & 80,00 & & & $1.200,00$ & $1.200,00$ & $1.200,00$ \\
\hline - Transporte adubo & tha- ${ }^{1}$ & 2,00 & 350,00 & & & 700,00 & 700,00 & 700,00 \\
\hline \multicolumn{9}{|l|}{ Colheita e beneficiamento } \\
\hline - Colheita & mão de obra & 40,00 & 30,00 & 40,00 & 40,00 & $1.200,00$ & $1.200,00$ & $1.200,00$ \\
\hline - Lavagem & mão de obra & 40,00 & 30,00 & 40,00 & 40,00 & $1.200,00$ & $1.200,00$ & $1.200,00$ \\
\hline - Transporte p/beneficiamento & Frete & 2,00 & 350,00 & & & 700,00 & 700,00 & 700,00 \\
\hline Custo total de produção & & & & 273,00 & 272,00 & $12.460,00$ & $12.460,00$ & $12.140,00$ \\
\hline Preço de priprioca em Santarém & $\mathrm{Kg}$ & 1,00 & 2,00 & & & & & \\
\hline RL área I (9 meses) & $\mathrm{Kg}_{\text {ha- }}{ }^{1}$ & $18.414,80$ & 2,00 & & & $36.829,60$ & $24.369,60$ & \\
\hline RL área I (12 meses) & Kg ha- ${ }^{1}$ & $22.097,00$ & 2,00 & & & $44.194,00$ & $31.734,00$ & \\
\hline RL área II (9 meses) & $\mathrm{Kg}_{\mathrm{ha}-}{ }^{1}$ & $11.088,00$ & 2,00 & & & $22.176,00$ & & $10.036,00$ \\
\hline RL área II (12 meses) & Kg ha- ${ }^{1}$ & $13.850,00$ & 2,00 & & & $27.700,00$ & & $15.560,00$ \\
\hline
\end{tabular}

$\mathrm{RB}=$ Rendimento Bruto

Área I = área com incorporação de adubo com enxada rotativa

$\mathrm{RL}=$ Rendimento Líquido

Área II = área sem incorporação de adubo com enxada rotativa

O custo de produção total na área experimental de Tabocal II foi de $\mathrm{R} \$ 12.460,00$. Diferentemente dos experimentos anteriores, $\mathrm{O}$ saldo assim que descontado os custos de produção foi positivo tanto aos nove como em doze meses de cultivo. Os lucros registrados na tabela mostram que o experimento que uso a enxada rotativa atingiu o valor de $R \$ 24.369,60$ aos nove meses e $\mathrm{R} \$ 31.734,00$ aos doze meses. Já o experimento com a adubação manual lucro $\mathrm{R} \$ 10.036,00$ aos nove meses e $\mathrm{R} \$ 15.560,00$ aos doze meses de cultivo. 


\section{Análise comparativa dos experimentos}

Partindo da proporcionalidade da mão de obra para implantação, manejo e cultivo da priprioca no oeste do Pará, este experimento se deparou com um ponto negativo com respeito à contratação da mão de obra, o que eleva os custos de produção de priprioca. Para estabelecer e manter as áreas capinadas foi preciso contratar o serviço de 267 diárias/hectare em Belterra e 380 diárias/hectare em Tabocal I. Tabocal II demandou 273 diárias para produzir um hectare de cultivo. As diárias demandadas nos experimentos mostram-se superiores à recomendação feita por Silva (2005) que é 156 diárias/hectare. Consequentemente, quanto maior o número de mão de obra contratado maior o custo de produção para produzir um hectare de priprioca, assim como verificado em Tabocal I. A razão da maior contratação de mão de obra derivou da dependência de mão de obra de comunidades distantes ao local do experimento, que muitas vezes elevou o custo das diárias de $\mathrm{R} \$ 30,00$ para $\mathrm{R} \$ 50,00$.

A partir dos rendimentos brutos dos experimentos e o desconto dos custos de produção, a margem de lucro ou rendimento líquido em Tabocal II foi maior se comparados ao experimento de Tabocal I e Belterra. Os fatores favoráveis criados pela mecanização, a fertilidade do solo, mais a incorporação de adubo verde $e$ esterco de frango na área de cultivo somam os resultados expressivos do experimento Tabocal II. As famílias parceiras que abraçaram este projeto mostraram interesse nos resultados de produção, com expectativas de cultivar e gerar uma nova alternativa econômica no campo.

Pelos resultados apresentados em todos os experimentos, os tubérculos que tinham um claro estresse hídrico aos nove meses de avaliação, tiveram aos doze meses (nova época chuvosa) uma recuperação hídrica e maior produção de tubérculos. Um novo estudo está sendo direcionado para determinar a qualidade olfativa por perfumistas do óleo coletado no verão e inverno.

Com relação aos cálculos de custo/benefício nos experimentos aos 12 meses do plantio, para cada $\mathrm{R} \$ 1,00$ investido no campo obter-se-ia um lucro de $\mathrm{R} \$ 0,15$ em Belterra e $\mathrm{R} \$ 0,42$ em Tabocal I, já em Tabocal II obter-se-ia R $\$ 2,54$ de lucro, considerando a comercialização a $\mathrm{R} \$ 2,00 / \mathrm{kg}$ de rizoma em Santarém.

\section{Extração de OE de priprioca em escala de laboratório, piloto e industrial}

A extração de óleo essencial de priprioca com equipamentos de laboratório mostrou que o Extrator Piloto de $150 \mathrm{~L}$ proporcionou um rendimento médio de $0,35 \%$, e o equipamento laboratorial Clevenger uma média de 0,49\% para Belterra, 0,58\% para Tabocal I, e 0,62\% para Tabocal II.

No teste industrial obtiveram-se $1.000 \mathrm{~kg}$ de tubérculos frescos de priprioca colhidos de $1.250 \mathrm{~m}^{2}$ do campo experimental de Tabocal Iem Santarém/PA. Após secagem dos tubérculos, com perda de aproximadamente $45 \%$ de umidade (em estufa para madeira) foram obtidos $550 \mathrm{~kg}$ de tubérculo seco de priprioca. Destes, foram transportados $485 \mathrm{~kg}$ para a empresa Beraca em Belém/PA para extração pelo sistema de arraste a vapor, obtendo-se $2,18 \mathrm{~kg}$ ou $0,45 \%$ em rendimento de óleo essencial.

Considerando o preço de US $\$ 500 / \mathrm{kg}$ OE de priprioca no mercado (valor indicado no mercado pela empresa MANE), o volume de óleo essencial produzido no melhor dos casos, em Tabocal II, com aprox. 22t de material fresco e de aprox. 11t de material seco, resultaria em $49,50 \mathrm{~kg} \mathrm{ha}^{-1} \mathrm{de}$ OE ou um faturamento de US\$24.750,00.

A remuneração das atividades de campo até a obtenção dos tubérculos de priprioca mostra um bom retorno financeiro se comparado a outros produtos agrícolas da região como o milho (Pedroso, 2012) com aprox. $\mathrm{R} \$ 900,00 /$ ha; soja (Castro et al., 2006) com aprox. R\$ 650/ha, e mandioca (Alves et al., 2011) que sofre com preços baixíssimos quando há excesso de oferta.

Há riscos inerentes ao processo de produção de priprioca na região. Acreditamos que o maior deles seja: não há demanda interna para o óleo essencial de priprioca; há uma única Empresa (Natura S/A) que utiliza este óleo essencial e sua demanda está garantida por fornecedores tradicionais na região de Belém; há uma baixa demanda vinda do exterior, e o principal motivo é o desconhecimento do óleo; já existe um óleo essencial originado do Cyperus scariosus no mercado externo.

Acreditamos que o $\mathrm{OE}$ de priprioca necessita de intensa divulgação para ser aceito no mercado externo, $e$ isto se faz em congressos especializados 
e de alto custo como o da IFEAT (International Federation of Essential Oils and Aroma Trades) $e$ outros. Amostras precisam ser distribuídas entre brockers, que são os intermediários que negociam mundialmente os óleos

\section{Análise cromatográfica do OE de priprioca cultivada no oeste do Pará}

As plantas aromáticas herbáceas, cultivadas em diferentes solos, eventualmente modificam o rendimento e principalmente seus princípios ativos (Brasil, 2006) que formam parte do aroma do $\mathrm{OE}$. Na indústria de perfumaria há uma exigência ampla sobre a padronização das fragrâncias que estão associadas à composição química do óleo essencial. A Figura 1 mostra pela via cromatográfica (GC-MS) o perfil da composição química dos OE de priprioca cultivados no município de Santarém e arredores.
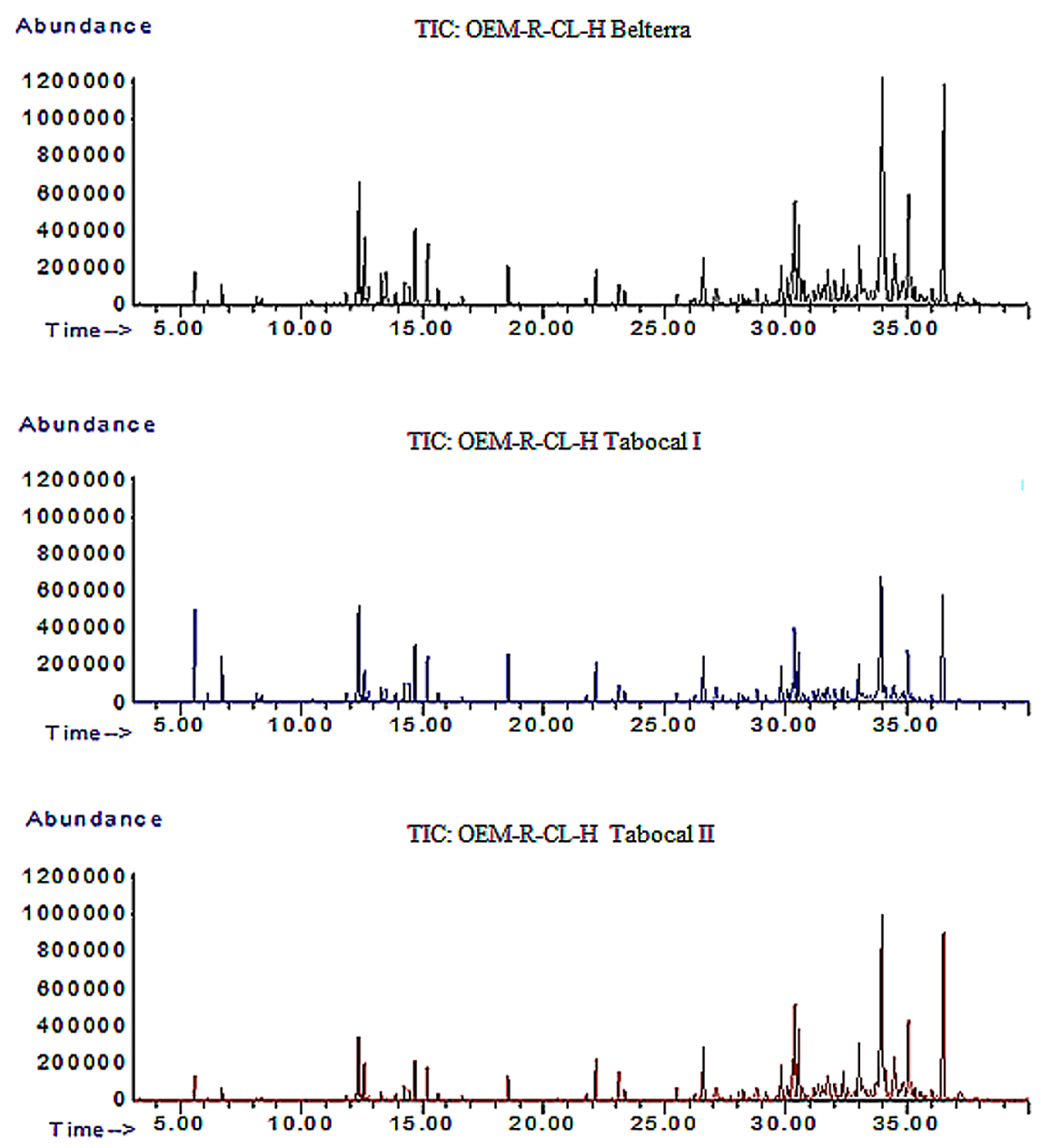

Figura 1 - Perfil cromatográfico do OE de priprioca de cultivos sob diferentes condições edafoclimáticas.

O perfil do óleo essencial da priprioca coletada em novembro de 2014 (período de verão na região) mostra as mesmas substâncias químicas com concentrações diferentes nos três perfis analisados, variações que podem ser resultado dos fatores climáticos e das condições físico-química dos solos.
Na Tabela 4 mostra-se que os compostos sesquiterpenos são majoritários incluindo a isocorimbolona, mustacona, aristolona, transpinocarveol e óxido de cariofileno. Os mesmos compostos já foram identificados na priprioca produzida na Região Metropolitana de Belém (Potiguara \& Zoghbi, 2008). Outros compostos 
com concentrações superiores a $2 \%$ também foram encontrados: mirtenol, viridifloreno, verbenona, 1,3,8-p-mentatrieno, pogostol, trans-calameneno, alfa-selineno, além de cinco outros compostos não identificados.

A Tabela 4 mostra também que os tubérculos de priprioca produzidos em solo arenoso têm uma concentração cinco vezes mais alta de alfa-pineno que os tubérculos produzidos em solos argilosos. Já o beta-pineno apresenta quase esta mesma concentração no solo arenoso.
Estas substâncias não são bem vindas para os perfumistas porque são muito comuns e tem aroma de pinhosol. Outros compostos como transpinocarveol, mirtenol, verbenona, alfa-copaeno, viridifloreno, alfa-selineno também mostram uma maior concentração quando os tubérculos são produzidos em solo arenoso. Por outro lado, a mustacona, substância que caracteriza a fragrância da priprioca, apresenta uma maior concentração em solo argiloso, tendo também uma importante concentração no solo arenoso.

Tabela 4 - Concentração dos compostos químicos do óleo essencial de priprioca em diferentes campos experimentais

\begin{tabular}{|c|c|c|c|c|c|}
\hline IR & Identificação & $\begin{array}{c}\text { Média } \\
\mathbf{t}_{\mathrm{R}}(\mathbf{m i n})\end{array}$ & $\begin{array}{c}\text { Belterra } \\
\text { (Solo Argiloso) }\end{array}$ & $\begin{array}{c}\text { Tabocal I } \\
\text { (Solo Arenoso) }\end{array}$ & $\begin{array}{c}\text { Tabocal I } \\
\text { (Solo Argiloso) }\end{array}$ \\
\hline 933 & $\alpha-$ pineno & 5,59 & 0,67 & 3,78 & 0,68 \\
\hline 977 & $\beta$-pineno & 6,73 & 0,46 & 2,08 & 0,39 \\
\hline 1126 & $\alpha$-canfolenal & 11,84 & 0,41 & 0,72 & 0,23 \\
\hline 1139 & trans-pinocarveol & 12,38 & 4,73 & 7,30 & 2,97 \\
\hline 1145 & 1,3,8-p-mentatrieno & 12,60 & 2,21 & 1,99 & 1,54 \\
\hline 1162 & pinocarvona & 13,29 & 1,05 & 0,97 & 0,35 \\
\hline 1167 & $\alpha$-felandren-8-ol & 13,49 & 1,12 & 0,84 & - \\
\hline 1186 & p-cimen-9-ol & 14,26 & 0,94 & 1,40 & - \\
\hline 1197 & mirtenol & 14,70 & 3,73 & 4,89 & 0,74 \\
\hline 1209 & verbenona & 15,22 & 2,19 & 3,12 & 2,18 \\
\hline 1375 & $\alpha$-copaeno & 22,15 & 1,25 & 2,73 & 1,58 \\
\hline 1397 & $\delta$-selineno & 23,09 & 0,72 & 1,26 & 1,89 \\
\hline 1485 & viridifloreno & 26,60 & 2,26 & 3,58 & 1,36 \\
\hline 1568 & $\alpha$-selineno & 29,82 & 1,86 & 2,61 & 2,80 \\
\hline 1574 & $\alpha$-bulneseno & 30,06 & 1,28 & 1,22 & 1,77 \\
\hline 1579 & trans-calameneno & 30,27 & 1,91 & 1,25 & 1,06 \\
\hline 1582 & óxido de cariofileno & 30,37 & 4,26 & 5,62 & 5,21 \\
\hline 1586 & n... ${ }^{2}$ & 30,55 & 3,45 & 3,81 & 4,02 \\
\hline 1591 & cis-calameneno & 30,72 & 1,24 & - & 0,81 \\
\hline 1617 & n... ${ }^{2}$ & 31,71 & 1,59 & 1,50 & 2,08 \\
\hline 1626 & trans-longepinocarveol & 32,02 & 1,41 & 1,38 & 1,56 \\
\hline 1635 & n... ${ }^{2}$ & 32,37 & 1,55 & 1,42 & 1,87 \\
\hline 1653 & pogostol & 33,04 & 2,64 & 2,42 & 3,17 \\
\hline 1679 & isocorimbolona & 33,99 & 15,19 & 13,66 & 14,76 \\
\hline 1682 & n.i. ${ }^{2}$ & 34,10 & 2,19 & 1,78 & 2,21 \\
\hline 1693 & n.i. ${ }^{2}$ & 34,50 & 3,76 & 2,04 & 4,13 \\
\hline 1709 & aristolona & 35,06 & 6,26 & 4,99 & 5,85 \\
\hline 1751 & mustacona & 36,52 & 14,25 & 8,69 & 10,30 \\
\hline
\end{tabular}




\section{Conclusão}

A produção de priprioca produzida comercialmente até então se concentrava na região metropolitana de Belém. Com os resultados experimentais 2012 e 2013, a produção de priprioca no Oeste do Pará apresenta-se como uma nova alternativa econômica para diversificar as áreas produtivas de pequenos ou grandes agricultores que cultivam comumente milho, soja, mandioca, etc., na região. Embora o custo de produção da priprioca seja elevado, acima de $\mathrm{R} \$ 12.000,00$, os resultados de produção de priprioca mostram-se satisfatórios e muito parecidos aos registradaos na região Metropolitana de Belém, mostrando que os fatores edafoclimáticos do Oeste do Pará não são limitantes na região. $\mathrm{O}$ experimento de Tabocal II foi o que mais se destacou, com 22,09t ha-1 de tubérculos frescos e aprox. 11,00t ha ${ }^{-1}$ de tubérculos secos aos 12 meses de cultivo. Quanto ao preço, é conservador propor a comercialização do tubérculo fresco no oeste do Pará em $\mathrm{R} \$ 2,00 / \mathrm{kg}$, diferentemente de Belém onde se comercializa para a Empresa Natura a R\$4,00/kg (merchandising). Ainda assim, o cultivo da priprioca no Oeste do Pará apresenta retornos atrativos, caso Tabocal I (R\$ 6.660,00/ ha $\left.^{-1}\right)$ e Tabocal II ( $\left.\mathrm{R} \$ 31.734,00 / \mathrm{ha}^{-1}\right)$.

Com referência à extração do óleo essencial produzida no oeste do Pará coloca-se em destaque a experimentação industrialda priprioca realizada em Belém, no intuito de incentivar futuras instalações de extração local. Os resultados mostram que é possível obter $49,50 \mathrm{~kg}$ ha ${ }^{-1}$ ou $0,45 \%$ de rendimento de $\mathrm{OE}$ em 11 toneladas de material seco. Este rendimento foi similar aos padrões de extração de $\mathrm{OE}$ da priprioca produzida em Belém pela empresa Beraca (consulta do autor). Com a comercialização do OE a US\$ 500,00/kg também proporcionaria uma lucratividade considerável apesar dos altos custos de produção. No entanto, há um concorrente potencial do OE de C. articulatus, o $\mathrm{OE}$ de $C$. scariosus comercializa mundialmente seu OE a um preço médio de US\$300,00/kg. Esta concorrência só será comprovada quando o óleo de priprioca este no mercado internacional.

Por último, as respectivas análises de solo ressaltam uma relação ampla sobre as diferentes concentrações de substâncias químicas do $\mathrm{OE}$ de cada experimento estudado. Estas podem ser usadas para uma futura padronização da priprioca na região. Já sua sustentabilidade na produção (que vai só ocorrendo na Amazônia brasileira) abre grandes chances de ampliar a aceitação da matéria prima pelas indústrias especializadas no setor de cosméticos e perfumaria do país e do mundo. Assim como a priprioca, outros produtos da biodiversidade da Amazônia podem ter esta mesma orientação de produção, agregando com isto, novas alternativas econômicas no campo agrícola e na indústria.

\section{Agradecimentos}

Ao Programa Nacional de Pós-Doutoramento da Coordenação de Aperfeiçoamento de Pessoal de Nível Superior pela bolsa de estudo e os recursos de pesquisa. À empresa Algine, que proporcionou a secagem de $1 \mathrm{t}$ de tubérculos; à empresa Horizonte Agronegócios, que concedeu 15t de adubo orgânico; à EMBRAPA/PA; à família Galo e ao agricultor Sr. Moreira, por conceder as áreas de cultivo; e ao Prof. Dr. Ilio Montanari Jr., pela contribuição neste artigo.

\section{Referências}

Adams CD. 1994. Cyperaceae. In: Davisse G, Sousa M \& Chater AO. (orgs.). Flora Mesoamericana, v. 6 Cidade de México: Universidad Nacional Autónoma de México. 82p.

Adams RP. 2007. Identification of essential oil components by gas chromatography/mass spectroscopy. Allured Publishing. 807p.

ALICEWED2. SECEX 2012. <http://aliceweb2.mdic. gov.br>. Acesso em: 06/01/2012.

Alves RNB, Júnior MSM, Cardoso CEL \& Nascimento, RP. 2011. Sistemas e custos de produção de raiz de mandioca desenvolvidos por agricultores de Castanhal - Pará, p;6-6. In: Anais ALICE. Maceió: ABAM: SBM. $\quad<$ http://www.alice.cnptia.embrapa.br/alice/ bitstream/doc/910944/1/Resumo17.pdf > . Acesso em: 01/10/2014.

Barata LES. Economia verde - Amazônia. Cienc. Cultural, 64(3): 31-35, 2012.

BRASIL. 2006. Boas Práticas Agrícolas (BPA) de plantas medicinais, aromáticas e condimentares. Plantas Medicinais \& Orientações Gerais para o Cultivo. Ed. preliminar Scheffer MC, Júnior CC; Coord.: Udry MC, Marques NE \& Kornijezuk RMP. Brasília: MAPA/SDC. $48 \mathrm{p}$. 
Castellani DC, Domenico CI, Roncoletta LMA, Silva AC, Tozaki RM \& Oliveira DH. Coeficientes técnicos de produção da priprioca (Cyperus articulatus L.) em sistema orgânico, na região de Belém (PA). Rev. Brasileira de Plantas Medicinais, Botucatu, 13: 606$611,2011$.

Castro SH, Reis RP \& Lima ALR. Custos de produção da soja cultivada sob sistema de Plantio direto: estudo de multicasos no oeste da Bahia. Ciência e Agrotecnologia, 30(6): 1146-1153, 2006.

Chamma da Amazônia. <https://www. chammadaamazonia.com.br $>$. Acesso em: 25/10/2020.

Cravo MS, Viégas IJM \& Brasil EC. 2010. Recomendações de adubação e calagem para o estado do Pará. Embrapa Amazônia Oriental, Belém. 262p.

Ferraz JBS. Perfumes da floresta amazônica em busca de uma alternativa sustentável. Ciência \& Cultura, 61(03): 40-43, 2009.

Fontanétti A, Carvalho G, Gomes LA, Almeida K, Moraes S \& Teixeira C. Adubação verde na produção orgânica de alface americana e repolho. Horticultura Brasileira, 24: 146-150, 2006.

Juruá, Natural da Amazônia. <http://www. juruacosmeticos.com>. Acesso em: 25/10/2020.

Lala's group. < http:/www.lalaessentialoils.com/cyprioloil.html>. Acesso em: 25/10/2020.

Maia JGS, Zoghbi MGB \& Andrade EHA. 2001. Plantas aromáticas na Amazônia e seus óleos essenciais. MPEG, Belém. 173p.
Ministério do Desenvolvimento Indústria e Comércio, Aliceweb. <http://aliceweb.mdic.gov.br//index/home>. Acesso em: 25/10/2020.

Moraes BC, Costa JMN, Costa ACL \& Costa MH. Variação espacial e temporal da precipitação no estado do Pará. Acta Amazônica, 35(2): 207-214, 2005.

Natura. <https://www.natura.com.br>. Acesso em: 25/10/2020.

Nicoli CML, Homma AOK, Matos GB \& Menezes A. 2006. Aproveitamento da biodiversidade amazônica: o caso da priprioca. EMBRAPA, Doc. 256, Belém. 27p.

Pedroso RS. Custo de produção de milho safrinha 2012.Fundação MS. Apresentação Power Point 2012. <www.granos.agr.br>. Acesso em: 21/10/2012.

Potyguara RCV \& Zoghbi MGB. 2008. Priprioca: um recurso aromático do Pará. Belém: MPEG, UEPA. 203p.

Silva AB. 2005. Estudo integrado da priprioca (Cyperus sp.) no estado do Pará. Dissertação (Mestrado em Agronomia). Instituto de Ciências Agrárias. Universidade Federal Rural da Amazônia, Belém. 101p.

Silva AF, Mitsuya M \& Da Silva R. 2013. Análise do índice pluviométrico da região de Santarém (PA), entre 1969 e 2010. In: Anais do 65ª Reunião Anual da SBPC. Universidade Federal de Pernambuco, RECIFE. 105p.

Teixeira LB, Oliveira RF, Furlan Júnior J, Campos PIF \& Germano VLC. 2006. Compostagem: lixo orgânico urbano e resíduos da agroindústria do açaí. Belém: Embrapa Amazônia Oriental, ALBRAS. 85p.

Biodiversidade Brasileira - BioBrasil.

Fluxo Contínuo

n. 3, 2021

http://www.icmbio.gov.br/revistaeletronica/index.php/BioBR

Biodiversidade Brasileira é uma publicação eletrônica científica do Instituto Chico Mendes de

Conservação da Biodiversidade (ICMBio) que tem como objetivo fomentar a discussão e a disseminação de experiências em conservação e manejo, com foco em unidades de conservação e espécies ameaçadas.

ISSN: 2236-2886 